Ambiente \& Água - An Interdisciplinary Journal of Applied Science
ISSN 1980-993X - doi:10.4136/1980-993X
www.ambi-agua.net
E-mail: ambi-agua@agro.unitau.br

\title{
Manganês, zinco, cádmio, chumbo, mercúrio e crômio no chorume de aterro sanitário em Dourados, MS, Brasil
}

\author{
doi: 10.4136/ambi-agua. 1538
}

Received: 10 Oct. 2014; Accepted: 21 Nov. 2014

\author{
Priscilla Fracalossi Riguetti ${ }^{1}$; Cláudia Andréa Lima Cardoso ${ }^{2}$; \\ Alberto Adriano Cavalheiro'; Ervim Lenzi ${ }^{3}$; Antonio Rogério Fiorucci ${ }^{2}$; \\ Margarete Soares da Silva ${ }^{2 *}$ \\ ${ }^{1}$ Centro Universitário da Grande Dourados (UNIGRAN), Dourados, MS, Brasil \\ ${ }^{2}$ Universidade Estadual de Mato Grosso do Sul (UEMS), Dourados, MS, Brasil \\ Programa de Pós Graduação em Recursos Naturais (PGRN) \\ ${ }^{3}$ Universidade Estadual de Maringá (UEM), Maringá, PR, Brasil \\ Departamento de Química (DQI) \\ *Autor correspondente: e-mail: margaret@uems.br, \\ priscillariguetti@hotmail.com, claudia@uems.br, albecava@uems.br, \\ ervimlenzi@gmail.com, arfiorucci@yahoo.com.br
}

\section{RESUMO}

Neste estudo analisaram-se as concentrações de manganês, zinco, cádmio, chumbo, mercúrio e crômio, em amostras de chorume coletado no aterro sanitário de Dourados/MS. Foram retiradas amostras de dois reservatórios, um com tratamento aeróbio e outro com tratamento anaeróbio. Foram realizadas quatro coletas de 2012 a 2013, compreendendo períodos de seca e de chuvas. As concentrações dos metais foram determinadas por espectrometria de absorção atômica, modalidade chama. A comparação de resultados entre os dois reservatórios e entre as coletas foi realizada empregando-se análise de variância com nível de confiança de 95\%. A análise dos resultados mostrou diferenças, quanto à concentração dos metais, somente entre as coletas. Os elementos manganês, zinco e chumbo apresentaram maiores concentrações nos períodos chuvosos e os demais elementos nos períodos de seca. De forma geral, apenas o índice pluviométrico interferiu nas concentrações dos metais estudados, também não se observaram variações de $\mathrm{pH}$ e condutividade elétrica ao longo do experimento.

Palavras-chave: condutividade, índice pluviométrico, metais pesados.

\section{Manganese, zinc, cadmium, lead, mercury and chromium in leachate from a landfill in Dourados, MS, Brazil}

\begin{abstract}
This study analyzed concentrations of manganese, zinc, cadmium, lead, mercury and chrome in leachate samples collected in the landfill of Dourados, Mato Grosso do Sul, Brazil. Samples from two ponds were taken, one undergoing aerobic treatment and the other undergoing anaerobic treatment. Four collections were made between 2012 and 2013, during dry seasons and rainy seasons. Metal concentrations were determined by atomic absorption
\end{abstract}


spectrometry, flame mode. Comparison between the results for both ponds and between the sample collections was done using analysis of variance with a 95\% accuracy level. Analysis results revealed differences in metal concentration within the samples, with the elements manganese, zinc and lead displaying higher concentrations during rainy periods and the other elements during droughts periods. Only the pluviometric index interfered in the studied metal concentrations and there were no variations in $\mathrm{pH}$ and electrical conductivity noticed throughout the experiment.

Keywords: conductivity, heavy metals, pluviometric index.

\section{INTRODUÇÃO}

Atualmente, a quantidade de resíduos sólidos urbanos (RSU) gerados pela sociedade é motivo de preocupação social, ambiental e de saúde pública. Esses resíduos são formados, basicamente, por matéria orgânica, papéis, vidros, plásticos e metais, sendo que muitos desses materiais são ricos em substâncias nocivas ao meio ambiente e à vida (Celere et al., 2007).

A quantidade de RSU gerados no Brasil, em 2013, foi de 76 milhões de toneladas. Desse montante, apenas 58,3\% foi depositado em aterros sanitários, o restante foi depositado em aterros controlados e lixões. Isso ocorreu em todos os Estados, sendo que nas regiões Norte, Nordeste e Centro Oeste estão $74 \%$ dos municípios que ainda utilizaram lixões e aterros controlados (ABRELPE, 2014). Considerando o Estado de Mato Grosso do Sul, apenas 27\% dos RSU foram destinados a aterros sanitários, $49 \%$ e $24 \%$, respectivamente, foram enviados a aterros controlados e lixões.

O aterro sanitário é mais adequado porque nele o solo é impermeabilizado, há sistemas de drenagem para líquidos e gases produzidos, o lixo é coberto com terra e compactado, entre outras medidas (Moreira et al., 2011). Nos aterros controlados e nos lixões não há impermeabilização e as substâncias provenientes da decomposição dos resíduos infiltram no solo atingindo águas subterrâneas e são carreadas pelas chuvas contaminando o meio ambiente. Outro agravante é que esses contaminantes irão persistir no ambiente até décadas após o fechamento do aterro (Cavallet et al., 2013; Santana et al., 2007).

No aterro sanitário a maior dificuldade é quanto ao destino do chorume coletado, pois é um efluente altamente contaminado e de difícil tratamento. Normalmente, o chorume é recirculado ou enviado para estações de tratamento de esgoto onde é submetido à degradação microbiológica e descartado, com o esgoto, em águas superficiais. Esse tratamento não é eficiente para chorume maduro, que apresenta nitrogênio amoniacal e substâncias húmicas, que são de difícil degradação e vários tipos de metais pesados (Morais et al., 2006).

A recirculação reduz a quantidade de compostos orgânicos e inorgânicos devido aos processos de adsorção, precipitação e complexação que ocorrem quando o chorume entra em contato com os resíduos aterrados e com o solo de cobertura, mas também não é uma solução permanente (Hipólito e Ezaki, 2006).

A grande dificuldade no tratamento do chorume deve-se ao fato dele ter composição química muito complexa. Ela pode variar de acordo com a natureza, forma de disposição e manejo dos resíduos, com a idade do aterro, com fatores climáticos, entre outros. De forma geral, pode-se dividir sua composição em quatro frações: matéria orgânica dissolvida, compostos orgânicos xenobióticos, macrocompostos inorgânicos como $\mathrm{Ca}, \mathrm{Mg}, \mathrm{Na}, \mathrm{K}, \mathrm{NH}^{4+}$, $\mathrm{Fe}, \mathrm{Cl}, \mathrm{SO}_{4}{ }^{2-}, \mathrm{HCO}_{3}{ }^{-}$, metais pesados e outros elementos potencialmente tóxicos como Cd, Cr, Cu, Pb, Mn, Ni, Zn, Hg, As, Ti, Se e Te (Morais et al., 2006; Moreira et al., 2011).

Os metais pesados reagem com ligantes difusores e com macromoléculas, o que lhes confere propriedades de bioacumulação, de biomagnificação na cadeia alimentar e persistência no ambiente, causando distúrbios nos processos metabólicos e danos aos sistemas 
biológicos de todos os seres vivos. Todos os metais bivalentes reagem facilmente com as proteínas através dos grupos tiois e amino, competindo com nutrientes essenciais.

O chumbo é absorvido pela proteína ligante do cálcio depositando-se nos ossos. Ele afeta todos os sistemas e órgãos do corpo humano, inclusive o sistema nervoso central e periférico (Moreira e Moreira, 2004).

O cádmio entra nas células sanguíneas, acumula-se nos rins, no fígado e nos músculos, podendo provocar lesão renal, irritação grave no estômago, enfraquecimento dos ossos e deformidades no esqueleto (Tavares e Carvalho, 1992).

O cromo, o manganês e zinco são elementos essenciais, mas, quando em excesso, são perigosos à saúde e ao equilíbrio ambiental. $\mathrm{O}$ cromo, no estado de oxidação hexavalente $\left(\mathrm{Cr}^{6+}\right)$ não tem função metabólica e é extremamente tóxico. Excesso de manganês pode causar distúrbios da fala e de memória e doenças degenerativas e excesso de zinco leva à interação competitiva com outros minerais essenciais à saúde (Cruz e Soares, 2011; Gomes et al., 2005; Sisinno, 2003).

Sendo assim, é necessário monitorar a concentração de metais pesados, como alerta ao descarte do chorume no ambiente. Na literatura encontraram-se estudos sobre metais pesados em chorume, mas não se encontrou monitoramento de forma sazonal. Assim, este estudo teve como objetivo monitorar as concentrações dos íons metálicos: cádmio $\left(\mathrm{Cd}^{2+}\right)$, chumbo $\left(\mathrm{Pb}^{2+}\right)$, cromo (Cr total), manganês $\left(\mathrm{Mn}^{2+}\right)$, mercúrio $\left(\mathrm{Hg}^{2+}\right)$ e zinco $\left(\mathrm{Zn}^{2+}\right)$, em amostras de chorume coletadas no aterro sanitário de Dourados, em épocas com diferentes índices pluviométricos.

O município de Dourados tem população estimada em 207.498 habitantes, com mais de 181.000 residindo em área urbana. O aterro sanitário foi construído em 2004, até então os RSU eram depositados num lixão. Em 2011 ele recebeu 64.422 toneladas de RSU, coletados de forma indiferenciada e produziu aproximadamente $12.480 \mathrm{~m}^{3}$ de chorume.

\section{MATERIAL E MÉTODOS}

No aterro, os resíduos dos serviços da saúde são aterrados em vala séptica e os demais são aterrados em trincheiras impermeabilizadas e com ductos para escoamento do chorume (Figura 1). O chorume bruto é conduzido até um tanque de homogeneização, na sequência ele passa por duas lagoas anaeróbias, para tratamento biológico e depois escoa para a lagoa facultativa, onde o tratamento é semiaeróbio, passando então para a lagoa 4, de maturação, onde o tratamento é aeróbio. Sempre que o volume da lagoa 4 atinge o limite máximo, o chorume é retirado e despejado sobre o aterro, passando pelo processo de recirculação. $\mathrm{O}$ escoamento entre as lagoas é permanente e a vazão varia de acordo com o índice pluviométrico.

A amostragem foi feita na lagoa anaeróbial e na lagoa 4. Em cada coleta foram preenchidos três frascos de $2000 \mathrm{~mL}$ para cada lagoa (triplicatas). O chorume depositado em cada frasco foi coletado de forma representativa: em diversos pontos da superfície da lagoa. As coletas ocorreram em outubro/2012 ( $1^{\mathrm{a}}$ coleta), fevereiro/2013 ( $2^{\mathrm{a}}$ coleta), agosto/2013 ( $3^{a}$ coleta) e novembro/2013 ( $4^{a}$ coleta) (Instituto Adolfo Lutz, 2008).

Imediatamente após a coleta, mediu-se a temperatura, a condutividade elétrica e o pH das amostras, em cada frasco. As medidas de temperatura e condutividade foram realizadas num condutivímetro Digimed DM31, com compensação automática de temperatura com referência de $25,0^{\circ} \mathrm{C}$. As medidas de $\mathrm{pH}$ foram feitas potenciometricamente em um pHmetro Micronal B474, com eletrodo de vidro combinado.

Do volume coletado foram retirados $1000 \mathrm{~mL}$ de cada frasco, para digestão. O procedimento de ataque químico foi: para cada $1000 \mathrm{~mL}$ de amostra foi acrescentado $5 \mathrm{~mL}$ de $\mathrm{HNO}_{3} 65 \%$, PA, Vetec. As soluções foram aquecidas em chapa elétrica, à temperatura de 
$80^{\circ} \mathrm{C}$, até volume de $40 \mathrm{~mL}$, sendo transferido, quantitativamente, para um balão volumétrico de $50 \mathrm{~mL}$ e o volume aferido com água deionizada (Instituto Adolfo Lutz, 2008).

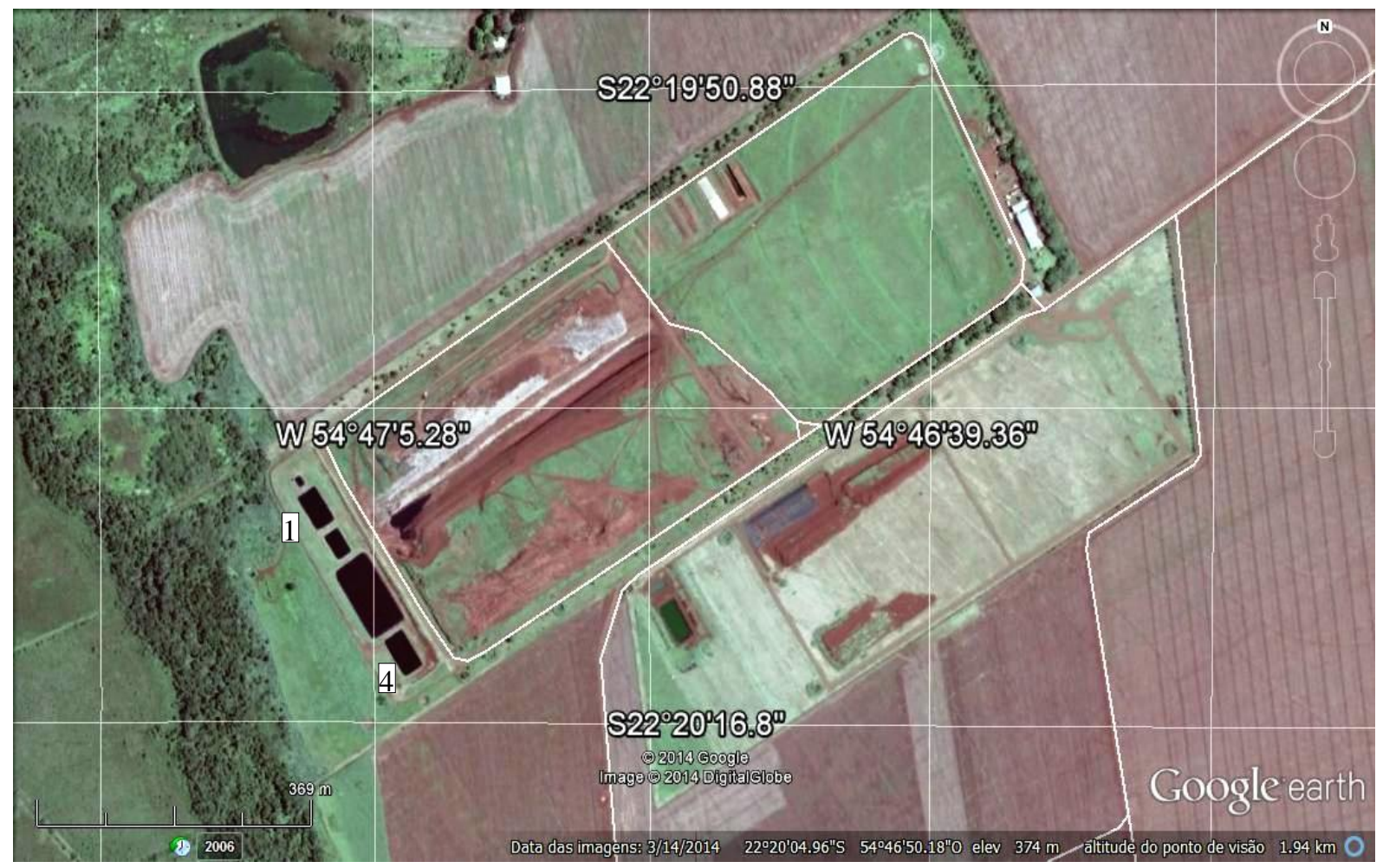

Figura 1. Vista aérea do aterro sanitário de Dourados, MS, Brasil. O reservatório menor é o tanque de homogeneização, na sequência têm-se as quatro lagoas de tratamento.

Fonte: Google Earth (2014).

A determinação da concentração dos metais foi feita por Espectrometria de Absorção Atômica, num espectrômetro Perkin Elmer AAnalyst 200, chama ar/acetileno, com lâmpadas de catodo oco, nos comprimentos de onda (nm): $\mathrm{Mn}=279,5 ; \mathrm{Zn}=213,9 ; \mathrm{Cd}=228,8 ; \mathrm{Pb}=$ 244,$8 ; \mathrm{Hg}=253,7$ e $\mathrm{Cr}=357,9$. Cada metal foi determinado por curva de calibração com os seguintes limites de detecção $\left(\mathrm{mg} \mathrm{L}^{-1}\right): \mathrm{Mn}=0,04 ; \mathrm{Zn}=0,020 ; \mathrm{Cd}=0,009 ; \mathrm{Pb}=0,025 ; \mathrm{Hg}=$ 0,016 e $\mathrm{Cr}=0,05$ (Keith, 1991).

O tratamento estatístico dos resultados foi realizado por análise de variância (ANOVA). Para comparação de resultados foi aplicado o teste de Tukey com nível de confiança de 95\%. Os cálculos foram realizados pelo Programa Estatístico Assistat 7.6 beta 2014.

\section{RESULTADOS E DISCUSSÃO}

Nas tabelas de resultados, a comparação estatística está indicada por vogais. Vogais iguais indicam que não houve diferença significativa entre os valores comparados. Há também os valores máximos permitidos para concentração de metais em efluentes líquidos, segundo Resolução $n^{\circ}$. 430/2011 do Conselho Nacional do Meio Ambiente - CONAMA, que dispõe sobre as condições e padrões de lançamento de efluentes (Brasil, 2011).

A concentração de metais, o $\mathrm{pH}$ e a condutividade elétrica do chorume podem variar em função da quantidade de água de chuvas que percola o aterro e do nível de decomposição da matéria orgânica presente no lixo. A degradação química e microbiológica dos resíduos acontece por etapas, que duram cerca de 15 anos (Cort et al., 2008).

O chorume novo (até 5 anos) é levemente ácido, tem $\mathrm{pH}$ menor que 7,0, pois predominam os ácidos voláteis e produtos nitrogenados sendo altamente biodegradável. Em 
aterros na fase metanogênica (acima de 5 anos) o pH é alcalino, superior a 8,0. Nesta fase, a decomposição da matéria orgânica é intensa com formação de gás carbônico $\left(\mathrm{CO}_{2}\right)$ e sais, principalmente bicarbonatos e sulfetos. Quanto maior for a quantidade de Sólidos Totais Dissolvidos (STD), maior será a condutividade do chorume (Athayde Júnior et al., 2009).

Todas as amostras apresentaram valores elevados de condutividade elétrica (Tabela 1), acima de $500 \mathrm{mS} \mathrm{m}^{-1}$. Isso indica que esse chorume é altamente poluidor podendo, ao longo do tempo, provocar a contaminação e a salinização de um provável ambiente receptor.

Tabela 1. Valores médios de temperatura, condutividade elétrica e $\mathrm{pH}$ das amostras de chorume coletadas no aterro sanitário de Dourados, MS, Brasil.

\begin{tabular}{|c|c|c|c|c|}
\hline Coletas & Lagoas & $\begin{array}{c}\text { Temperatura } \\
\left({ }^{\circ} \mathrm{C}\right)\end{array}$ & $\begin{array}{c}\text { Condutividade } \\
\text { Elétrica }\left(\mathrm{mS} \mathrm{m}^{-1}\right)\end{array}$ & $\mathbf{p H}$ \\
\hline \multirow[t]{2}{*}{$1^{\mathrm{a}}$ coleta } & Lagoa 1 & $29,7^{\circ} \pm 0,1$ & $838 \pm 1$ & $8,16 \pm 0,01$ \\
\hline & Lagoa 4 & $29,2^{\circ} \pm 0,1$ & $585 \pm 4$ & $8,27 \pm 0,01$ \\
\hline \multirow[t]{2}{*}{$2^{\mathrm{a}}$ coleta } & Lagoa 1 & $28,4 \pm 0,0$ & $603 \pm 14$ & $8,07 \pm 0,00$ \\
\hline & Lagoa 4 & $28,4 \pm 0,0$ & $592 \pm 10$ & $8,47 \pm 0,00$ \\
\hline \multirow[t]{2}{*}{$3^{a}$ coleta } & Lagoa 1 & $25,8 \pm 0,4$ & $719 \pm 12$ & $8,15 \pm 0,01$ \\
\hline & Lagoa 4 & $25,7 \pm 0,3$ & $510 \pm 11$ & $8,20 \pm 0,01$ \\
\hline \multirow[t]{2}{*}{$4^{\mathrm{a}}$ coleta } & Lagoa 1 & $29,3 \pm 0,1$ & $651 \pm 7$ & $8,13 \pm 0,07$ \\
\hline & Lagoa 4 & $28,8 \pm 0,1$ & $541 \pm 1$ & $8,19 \pm 0,02$ \\
\hline CONAMA & & 40 & --- & 5 a 9 \\
\hline
\end{tabular}

Nota: --- Valor não referenciado na Resolução nº. 430/2011 (Brasil, 2011).

Vários autores avaliaram áreas contaminadas por lixões, por aterros e ambientes que receberam despejo de chorume. Todos detectaram condutividade elevada (Moreira et al., 2011; Sisinno e Moreira, 1996).

Os valores de $\mathrm{pH}$ entre 8,0 e 8,5 indicam a predominância de chorume proveniente de resíduos em estado avançado de decomposição. Como o aterro ainda está em operação, o chorume provém de resíduos em diferentes estágios de decomposição, mas a recirculação favorece o envelhecimento do mesmo.

Para se verificar a influência do índice pluviométrico (Figura 2) na concentração dos metais, no $\mathrm{pH}$ e na condutividade elétrica do chorume, as coletas foram realizadas em épocas com diferentes índices: outubro/2012 (139,6mm), fevereiro/2013 (223,5 mm), agosto/2013 $(4,2 \mathrm{~mm})$ e novembro/2013 $(74,8 \mathrm{~mm})$.

Os resultados não apontaram diferenças significativas de $\mathrm{pH}$ nem de condutividade elétrica, somente de concentração.

Conforme Hipólito e Ezaki (2006), o conteúdo total de metais num aterro corresponde ao somatório dos íons presentes no lixo, no chorume e no solo de cobertura. Eles estão, em grande parte, nos resíduos de origem e dependendo do tipo de resíduo, a lixiviação é muito lenta. No chorume bruto os íons ficam associados às partículas coloidais (orgânicas e inorgânicas) e na forma de complexos, o pH alcalino torna o meio redutor fazendo com que os íons metálicos sejam precipitados na forma de sulfetos, sulfatos, carbonatos e oxi-hidróxidos. Quando há recirculação também pode ocorrer retenção de metais no solo de cobertura por processos de adsorção e precipitação resultante do contato chorume/solo/lixo. 


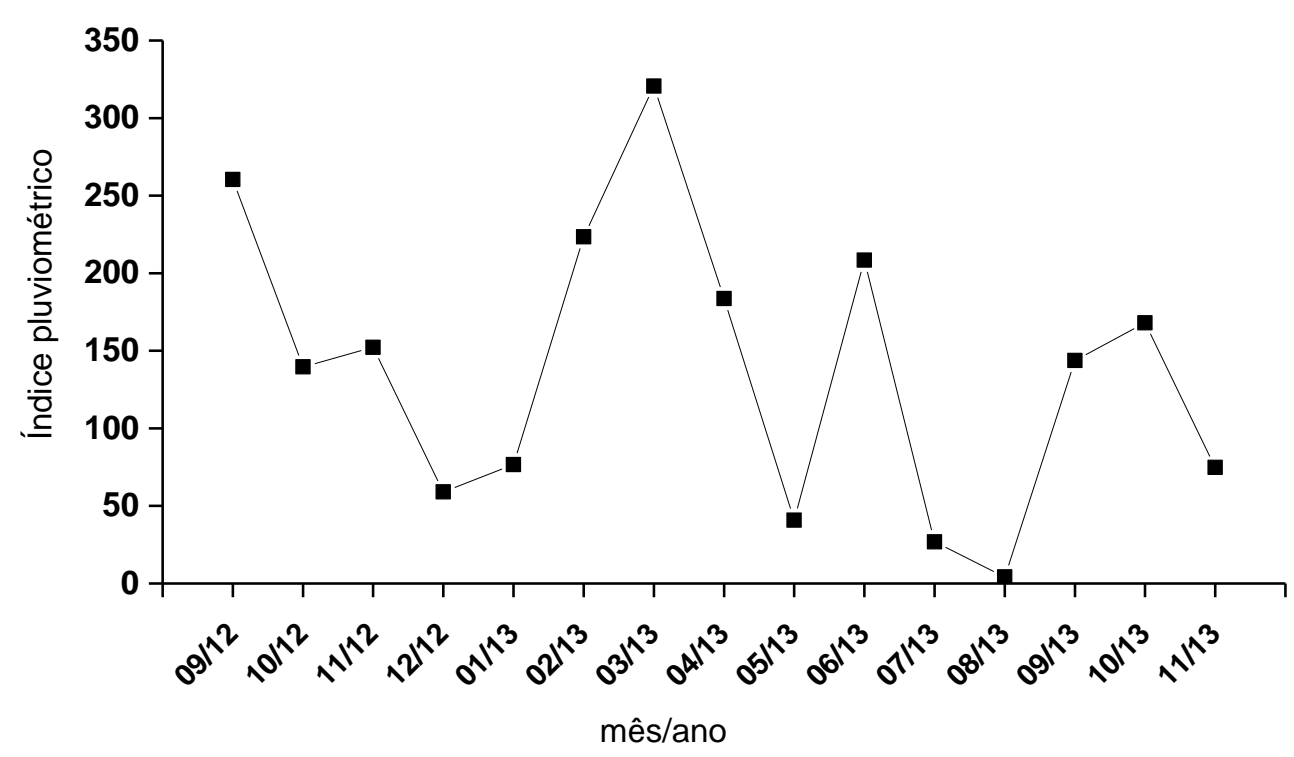

Figura 2. Variação do índice pluviométrico no município de Dourados, no período compreendido entre as coletas de chorume no aterro sanitário (EMBRAPA, 2014).

A comparação de resultados de concentração, entre as coletas (Tabela 2), foi feita com o intuito de se analisar a influência do índice pluviométrico sobre as mesmas. Nas coletas realizadas em outubro de 2012 e fevereiro de 2013, meses com maior precipitação, foram determinadas concentrações acima do limite de detecção, somente para manganês, zinco, e chumbo e nas coletas realizadas em agosto e novembro de 2013, meses com menor precipitação foram determinados também traços de cádmio, mercúrio e crômio.

Tabela 2. Comparação, entre as coletas, dos valores médios determinados para os metais, nas amostras de chorume coletadas no aterro sanitário de Dourados, MS, Brasil.

\begin{tabular}{|c|c|c|c|c|c|c|}
\hline \multirow[t]{2}{*}{ Amostras } & \multicolumn{6}{|c|}{ Concentrações $\left(\mathrm{mg} \mathrm{L}^{-1}\right)$} \\
\hline & Mn & $\mathbf{Z n}$ & $\mathbf{P b}$ & $\mathbf{C d}$ & Hg & Cr (total) \\
\hline \multicolumn{7}{|l|}{ Lagoa 1} \\
\hline $1^{\mathrm{a}}$ coleta & $1,97 \mathrm{a}$ & $0,270 \mathrm{a}$ & $0,335 \mathrm{~b}$ & nd & nd & nd \\
\hline $2^{\mathrm{a}}$ coleta & $1,34 \mathrm{~b}$ & $0,127 \mathrm{~b}$ & $0,587 \mathrm{a}$ & nd & nd & nd \\
\hline $3^{a}$ coleta & $0,83 \mathrm{c}$ & $0,099 \mathrm{~b}$ & $0,066 \mathrm{c}$ & 0,010 & $0,018 \mathrm{~b}$ & 0,02 \\
\hline $4^{\mathrm{a}}$ coleta & $0,06 \mathrm{~d}$ & $0,002 \mathrm{c}$ & $0,006 \mathrm{~d}$ & nd & $0,165 \mathrm{a}$ & 0,01 \\
\hline $\mathrm{CV} \%$ & 1 & 11 & 3 & --- & 3 & --- \\
\hline \multicolumn{7}{|l|}{ Lagoa 4} \\
\hline $1^{\mathrm{a}}$ coleta & $2,59 \mathrm{a}$ & $0,075 \mathrm{a}$ & $0,078 \mathrm{~b}$ & nd & nd & nd \\
\hline $2^{\mathrm{a}}$ coleta & $0,77 \mathrm{c}$ & $0,053 \mathrm{~b}$ & $1,280 \mathrm{a}$ & nd & nd & nd \\
\hline $3^{\mathrm{a}}$ coleta & $0,81 \mathrm{~b}$ & $0,044 \mathrm{~b}$ & $0,021 \mathrm{c}$ & 0,005 & 0,008 & 0,02 \\
\hline $4^{\mathrm{a}}$ coleta & $0,06 \mathrm{~d}$ & $0,001 \mathrm{c}$ & $0,004 \mathrm{c}$ & nd & 0,092 & 0,01 \\
\hline $\mathrm{CV} \%$ & 1 & 9 & 5 & --- & --- & --- \\
\hline CONAMA* & 1,0 & 5,0 & 0,5 & 0,2 & 0,01 & 0,05 \\
\hline
\end{tabular}

Nota: nd: elemento não detectado. CV\%: coeficiente de variação. --- Valores não calculados devido a várias amostras apresentarem concentração abaixo do limite de detecção do método de análise.

*Valores máximos permitidos pela Resolução nº. 430/2011 (Brasil, 2011). 
Na maioria das análises, as concentrações de manganês, zinco e chumbo foram maiores na $1^{\mathrm{a}}$ e na $2^{\mathrm{a}}$ coleta, para as duas lagoas, indicando que o maior volume de água no aterro influenciou na disponibilidade e mobilidade desses elementos.

Verifica-se que o manganês apresentou diferença de concentração entre todas as coletas, em ambas as lagoas. Os maiores valores foram determinados na $1^{\text {a }}$ coleta: $1,97 \mathrm{mg} \mathrm{L}^{-1}$ na lagoa 1 e $2,59 \mathrm{mg} \mathrm{L}^{-1}$ na lagoa 4 . A $1^{\text {a }}$ coleta ocorreu no mês com $2^{\circ}$ maior índice pluviométrico, indicando que o aumento da concentração foi proporcional ao volume de água no aterro até certo limite pois, diminuiu na $2^{\circ}$ coleta, que foi um mês com volume de chuva muito superior ao da $1^{\text {a }}$ coleta. $\mathrm{O}$ volume de água que percolou o aterro aumentou a disponibilidade e mobilidade desse metal, mas verifica-se também a influência da diluição do chorume, que foi muito maior na $2^{\circ}$ coleta.

Para o zinco, observou-se diferença de concentrarão entre as $1^{\mathrm{a}}, 2^{\mathrm{a}}$ e $4^{\mathrm{a}}$ coletas, não havendo diferença entre a $2^{a}$ e $3^{a}$ coletas, tanto na lagoa 1 quanto na lagoa 4 . Os maiores valores foram determinados na lagoa 1 sendo, $0,270 \mathrm{mg} \mathrm{L}^{-1}$ na $1^{\mathrm{a}}$ coleta e $0,127 \mathrm{mg} \mathrm{L}^{-1}$ na $2^{\mathrm{a}}$ coleta. Para a lagoa 4, o maior valor foi $0,075 \mathrm{mg} \mathrm{L}^{-1}$ na $1^{\mathrm{a}}$ coleta. A influência do volume de chuvas sobre a concentração do zinco foi idêntica à do manganês.

Para o chumbo foi observado diferença de concentração entre todas as coletas realizadas na lagoa 1 e entre a $1^{a}, 2^{a}$ e $3^{a}$ coleta da lagoa 4 , não havendo diferença entre a $3^{a}$ e $4^{a}$ coleta. Diferentemente, os maiores valores foram determinados na $2^{\mathrm{a}}$ coleta: $0,587 \mathrm{mg} \mathrm{L}^{-1}$ na lagoa 1 e $1,280 \mathrm{mg} \mathrm{L}^{-1}$ na lagoa 4 . Neste caso, a diluição do chorume não reduziu a concentração indicando que a disponibilidade e mobilidade do chumbo foi maior que a do manganês e do zinco. Oliveira e Santana (2010) observaram aumento da concentração de chumbo em águas contaminadas por aterro, em períodos de chuva, também mostrando maior mobilidade desse elemento nessa época.

Verifica-se também que os menores valores determinados para o manganês, o zinco e o chumbo foram os da $4^{\text {a }}$ coleta, que ocorreu após o período de seca. Ocorreu que, no final do período de chuvas (após a $2^{\mathrm{a}}$ coleta) houve retirada de chorume da lagoa 4 então, o aumento do índice pluviométrico nos dois meses que antecederam a $4^{\mathrm{a}}$ coleta provocou diluição do chorume das lagoas, mas não foi suficiente para carreá-los do aterro, diminuindo a concentração desses metais no chorume. Além desse fator, o $\mathrm{pH}$ alcalino, continuamente, favorece a precipitação dos metais para o fundo das lagoas e a imobilização deles no lodo já que o mesmo é rico em matéria orgânica persistente à degradação microbiológica (Morais et al., 2006).

Os metais que, em algumas coletas, apresentaram concentração acima do estabelecido pela legislação foram: manganês, chumbo e mercúrio. $O$ manganês excedeu na $1^{\mathrm{a}}$ e na $2^{\mathrm{a}}$ coleta, na lagoa 1 e o chumbo excedeu na $2^{\text {a }}$ coleta, nas duas lagoas, ambos em período de maior precipitação. O mercúrio apresentou concentrações acima da legislação na $3^{\mathrm{a}}$ e na $4^{\mathrm{a}}$ coleta, sendo o que mais excedeu o limite, com concentração 16,5 vezes superior a do limite estabelecido, na $4^{\mathrm{a}}$ coleta da lagoa 1 . Oliveira e Santana (2010) também verificaram excesso de chumbo e manganês, inclusive em períodos mais chuvosos, mas não de mercúrio.

A principal fonte de mercúrio, de chumbo e de zinco é a matéria orgânica resultante da decomposição do lixo. Os metais ferrosos e galvanizados, os plásticos e os papéis também são fontes de chumbo, de zinco e cádmio. O manganês é utilizado em baterias, porcelanas, etc. Os metais estão presentes também em lâmpadas, pilhas, restos de produtos químicos, eletrônicos e vários outros resíduos que vão para o aterro por coleta indiferenciada (Celere et al., 2007; Cort et al., 2008).

Quanto à comparação entre as lagoas 1 e 4 (Tabela 3), não foi possível fazer o cálculo estatístico para todas as coletas, devido às concentrações estarem muito próximo ou abaixo do limite de detecção. Considerando as coletas individualmente, observa-se que houve diferença entre as lagoas, para todos os metais determinados, exceto para o manganês na $3^{\text {a }}$ coleta. 
Tabela 3. Comparação, entre lagoas, dos valores médios determinados, para os metais, em cada coleta, nas amostras de chorume coletadas no aterro sanitário de Dourados, MS, Brasil.

\begin{tabular}{|c|c|c|c|c|c|c|c|}
\hline \multirow[t]{2}{*}{ Coletas } & \multirow[t]{2}{*}{ Lagoas } & \multicolumn{6}{|c|}{ Concentrações (mg L $\left.{ }^{-1}\right)$} \\
\hline & & Mn & $\mathbf{Z n}$ & $\mathbf{P b}$ & $\mathbf{C d}$ & $\mathrm{Hg}$ & Cr (total) \\
\hline \multirow[t]{3}{*}{$1^{\mathrm{a}}$ coleta } & Lagoa 1 & $1,97 \mathrm{~b}$ & $0,270 \mathrm{a}$ & $0,335 \mathrm{a}$ & nd & nd & nd \\
\hline & Lagoa 4 & $2,59 \mathrm{a}$ & $0,075 \mathrm{~b}$ & $0,078 \mathrm{~b}$ & nd & nd & nd \\
\hline & $\mathrm{CV} \%$ & 0,8 & 9 & 3 & --- & --- & --- \\
\hline \multirow[t]{3}{*}{$2^{a}$ coleta } & Lagoa 1 & $1,34 \mathrm{a}$ & $0,127 \mathrm{a}$ & $0,586 \mathrm{~b}$ & nd & nd & nd \\
\hline & Lagoa 4 & $0,77 \mathrm{~b}$ & $0,053 \mathrm{~b}$ & $1,280 \mathrm{a}$ & nd & nd & nd \\
\hline & $\mathrm{CV} \%$ & 1 & 12 & 2 & --- & --- & --- \\
\hline \multirow[t]{3}{*}{$3^{a}$ coleta } & Lagoa 1 & $0,83 \mathrm{a}$ & --- & $0,066 \mathrm{a}$ & --- & --- & --- \\
\hline & Lagoa 4 & $0,81 \mathrm{a}$ & --- & $0,021 b$ & --- & --- & --- \\
\hline & $\mathrm{CV} \%$ & 2 & --- & 5 & --- & --- & --- \\
\hline \multirow[t]{3}{*}{$4^{\mathrm{a}}$ coleta } & Lagoa 1 & --- & --- & --- & --- & $0,165 \mathrm{a}$ & --- \\
\hline & Lagoa 4 & --- & --- & --- & --- & $0,092 \mathrm{~b}$ & --- \\
\hline & CV\% & --- & --- & --- & --- & 2 & --- \\
\hline CONAMA* & & 1,0 & 5,0 & 0,5 & 0,2 & 0,01 & 0,05 \\
\hline
\end{tabular}

Nota: nd: elemento não detectado. CV\%: coeficiente de variação. --- Valores não calculados pelo programa devido às amostras apresentarem valores de concentração muito próximos ou abaixo do limite de detecção. *Valores máximos permitidos pela Resolução nº. 430/2011 (Brasil, 2011).

Para a maioria das coletas, a concentração dos metais determinados na lagoa 1, que contem o chorume em sua primeira fase de tratamento, foram superiores às concentrações determinadas na lagoa 4, exceto para o manganês, nas $1^{\mathrm{a}}$ e $3^{\mathrm{a}}$ coletas e para o chumbo na $2^{\mathrm{a}}$ coleta. Cort et al. (2008) também verificaram concentrações maiores de zinco, de manganês, de cádmio, de chumbo e de crômio no chorume bruto em relação ao chorume tratado.

Apesar de, na análise individual das coletas, se observarem diferenças entre as lagoas, quando se considera a média de todas as coletas (Tabela 4), verifica-se pouca influência do tratamento ao qual a lagoa é submetida, na concentração dos metais. Nesta comparação, somente o zinco apresentou maior concentração na lagoa 1.

Tabela 4. Comparação entre as lagoas, considerando o valor médio de todas as coletas, para cada metal determinado nas amostras de chorume do aterro sanitário de Dourados, MS, Brasil.

\begin{tabular}{lcccccc}
\hline \multirow{2}{*}{ Lagoas } & $\mathbf{7}$ Concentrações $\left(\mathbf{m g ~ L}^{-\mathbf{1}}\right)$ \\
\cline { 2 - 7 } & $\mathbf{M n}$ & $\mathbf{Z n}$ & $\mathbf{P b}$ & $\mathbf{C d}$ & $\mathbf{H g}$ & $\mathbf{C r}$ (total) \\
\hline Lagoa 1 & $1,05 \mathrm{a}$ & $0,124 \mathrm{a}$ & $0.248 \mathrm{a}$ & $0.002 \mathrm{a}$ & $0,045 \mathrm{a}$ & $0,007 \mathrm{a}$ \\
Lagoa 4 & $1,06 \mathrm{a}$ & $0,043 \mathrm{~b}$ & $0.345 \mathrm{a}$ & $0.001 \mathrm{a}$ & $0,025 \mathrm{a}$ & $0,007 \mathrm{a}$ \\
CV (\%) & 81 & 95 & 146 & 190 & 166 & 115 \\
CONAMA* & 1,0 & 5,0 & 0,5 & 0,2 & 0,01 & 0,05 \\
\hline
\end{tabular}

Nota: CV\%: coeficiente de variação. *Valores máximos permitidos pela Resolução n ${ }^{\circ} .430 / 2011$ (Brasil, 2011).

Considerando a média de todas as coletas, somente o mercúrio apresentou concentração muito superior ao limite estabelecido pela legislação. 


\section{CONCLUSÃO}

Devido ao tempo de funcionamento do aterro, agravado pelo processo de recirculação, o chorume apresentou $\mathrm{pH}$ básico, o que favorece a precipitação e complexação de metais. Esse fato influencia na concentração dos metais no chorume e pode torná-la não representativa do montante que realmente há no aterro.

O índice pluviométrico interfere na concentração dos metais no chorume, devido as suas diferenças de mobilidade e disponibilidade no material aterrado.

Considerando as coletas individualmente, os metais chumbo, manganês e mercúrio excederam os limites estabelecidos pela legislação, o que mais excedeu foi o mercúrio, atingindo concentração 16,5 vezes superior a do limite estabelecido. Isso mostra a relevância de uma análise prévia do chorume e tratamento do mesmo, antes de qualquer destino que possa impactar o meio, seja como fertilizante, despejo em ambientes aquáticos ou estações de tratamento de esgoto, entre outros.

Quanto ao tratamento anaeróbio-aeróbio, de forma geral, não houve diferenciação entre as lagoas, exceto para o zinco, que apresentou concentração maior na lagoa 1, que tem tratamento anaeróbio. Conclui-se que os processos de degradação biológica da matéria orgânica não interferiram, de maneira relevante, na disponibilização dos metais determinados.

Apesar da concentração da maioria dos elementos estarem abaixo do estabelecido, o descarte do chorume no ambiente, sem tratamento, é preocupante, levando-se em consideração o efeito cumulativo e tóxico de todos os metais determinados.

Todas as amostras analisadas apresentaram condutividade elevada, indicando a presença de grande quantidade de sólidos totais dissolvidos no chorume.

Para que o efluente analisado neste estudo seja descartado no ambiente é necessário fazer correções de $\mathrm{pH}$, de condutividade elétrica, controlar as quantidades de STD e de metais pesados, dentre outras substâncias nocivas à saúde e ao meio ambiente.

\section{AGRADECIMENTOS}

À administração do Aterro Sanitário de Dourados que permitiu acesso ao local e material de estudo, ao Laboratório de Agroquímica e Meio Ambiente da Universidade Estadual de Maringá-PR, que realizou as análises por espectrometria de absorção atômica, ao Programa de Pós Graduação em Recursos Naturais - PGRN/UEMS onde a pesquisa foi desenvolvida e à CAPES pelo suporte financeiro PROAP/CAPES n802116/2014.

\section{REFERÊNCIAS}

ASSOCIAÇÃO BRASILEIRA DE EMPRESAS DE LIMPEZA PÚBLICA E RESÍDUOS ESPECIAIS - ABRELPE. Panorama de resíduos sólidos no Brasil 2013. São Paulo: Grapa, 2014. 114p.

ATHAYDE JÚNIOR, G. B.; NÓBREGA, C. C.; GADELHA, C. L. M.; SOUZA, I. M. F.; FAGUNDES, G. S. Efeito do antigo Lixão do Roger, João Pessoa, Brasil, na qualidade de água subterrânea local. Revista Ambient. Água, Taubaté, v. 4, n. 1, p. 142-155, 2009. http://dx.doi.org/10.4136/ambi-agua.79

BRASIL. Resolução CONAMA n 430, de 13 de maio de 2011. Dispõe sobre condições e padrão de lançamento de efluentes, complementa e altera a Resolução n ${ }^{\circ} 357$, de 17 de março de 2005, do Conselho Nacional do Meio Ambiente - CONAMA. Diário Oficial [da] União. Brasília, 16 mai. 2011. 
CAVAllET, L. E.; CARVALHO, S. G. de; FORTES NETO, P. Metais pesados no rejeito e na água em área de descarte de resíduos sólidos urbanos. Revista Ambient. Água, Taubaté, v. 8 n. 3, p 229-238, 2013. http://dx.doi.org/10.4136/ambi-agua.1155

CELERE, M. S.; OLIVEIRA, A. S.; TREVIlATO, T. M. B.; SEGURA-MUÑOZ, S. I. Metais pesados presentes no chorume coletado no aterro sanitário de Ribeirão Preto, São Paulo, Brasil e sua relevância para saúde pública. Cadernos de Saúde Pública, Rio de Janeiro, v. 23, n. 4, p. 939-947, 2007. http://dx.doi.org/10.1590/S0102311X2007000400021

CORT, E. P. D.; ALBERTI, V.; ROTTA, M.; BECEGATO, V.; MACHADO, W. C. P.; ONOFRE, S. B. Níveis de metais pesados presentes no chorume produzido em aterros sanitários da região sudoeste do Paraná. Geoambiente, Jataí, n. 11, p. 103-116, 2008.

CRUZ, J. B. F.; SOARES, H. F. Uma revisão sobre o zinco. Ensaios e Ciência: Ciências Biológicas, Agrárias e da Saúde, Valinhos, v. 15, n. 1, p. 207-222, 2011.

EMPRESA BRASILEIRA DE PESQUISA AGROPECUÁRIA - EMBRAPA. Guia clima. Estação da Embrapa Agropecuária Oeste - Dourados/MS. Disponível em: <http://www.cpao.embrapa.br/clima/?lc=site/banco-dados/base_dados $>$. Acesso em: 10 nov. 2014.

GOOGLE EARTH. Vista aérea do aterro sanitário de Dourados, MS, Brasil. Imagem de 14/03/2014. Coordenadas: 22²0’04,96”S E 5446’50,18’O. Elevação 375 M.

GOMES, M. R.; ROGERO M. M.; TIRAPEGUI, J. Considerações sobre cromo, insulina e exercício físico. Revista Brasileira de Medicina do Esporte, São Paulo, v. 11, n. 5, p. 262-266, 2005. http://dx.doi.org/10.1590/S1517-86922005000500003

HYPÓLITO, R.; EZAKI, S. Íons de metais pesados em sistema solo-lixo-chorume-água de aterros sanitários da região metropolitana de São Paulo. Águas Subterrâneas, São Paulo, v. 20, n. 1, p. 99-114, 2006.

INSTITUTO ADOLFO LUTZ. Métodos físico-químicos para análise de alimentos. 4. ed. São Paulo: Instituto Adolfo Lutz, 2008. 1020 p.

KEITH, L. H. Compilation of EPA's Sampling and analysis methods. 2. ed. New York: Lewis Publishers, 1991. 803 p.

MORAIS, J. L.; SIRTORI, C.; PERALTA-ZAMORA, G. Tratamento de chorume de aterro sanitário por fotocatálise heterogênea integrada a processo biológico convencional. Química Nova, São Paulo, v. 29, n. 1, p. 20-23, 2006. http://dx.doi.org/10.1590/S010040422006000100005

MOREIRA, C. A.; OIVEIRA, M. T. de; SILVA, A. C. da. Estudo geofísico em aterro controlado disposto sobre rochas fraturadas. Revista Ambient. Água, Taubaté, v. 6, n. 2, p. 180-190, 2011. http://dx.doi.org/10.4136/ambi-agua.193

MOREIRA, F. R.; MOREIRA J. C. Os efeitos do chumbo sobre o organismo humano e seu significado para a saúde. Revista Panamericana de Salud Pública, Washington, v. 15, n. 2, p. 119-29, 2004.

OLIVEIRA, D. L.; SANTANA, G. P. Influência do aterro municipal de Manaus sobre as águas superficiais da circunvizinhança: um enfoque ao estudo de metais pesados. Caminhos de Geografia, Uberlândia, v. 11, n. 34, p. 75-83, 2010. 
SANTANA, G. P.; BARRONCAS, P. S. R. Estudo de metais pesados $(\mathrm{Co}, \mathrm{Cu}, \mathrm{Fe}, \mathrm{Cr}, \mathrm{Ni}$, $\mathrm{Mn}, \mathrm{Pb}$ e $\mathrm{Zn}$ ) na Bacia do Tarumã-Açu Manaus-AM. Acta Amazônica, Manaus, v. 37, n. 1, p. 111-118, 2007. http://dx.doi.org/10.1590/S0044-59672007000100013

SISINNO, C. L. S. Disposição em aterros controlados de resíduos sólidos industriais nãoinertes: avaliação dos componentes tóxicos e implicações para o ambiente e para a saúde humana. Cadernos de Saúde Pública, Rio de Janeiro, v. 19, n. 2, p. 369-374, 2003. http://dx.doi.org/10.1590/S0102-311X2003000200003

SISINNO, C. L. S.; MOREIRA, J. C. Avaliação da contaminação e poluição ambiental na área de influência do aterro controlado do Morro do Céu, Niterói, Brasil. Cadernos de Saúde Pública, Rio de Janeiro, v. 12, n. 4, p. 515-523, 1996. http://dx.doi.org/10.1590/S0102-311X1996000400010

TAVARES, T. M.; CARVALHO, F. M. Avaliação de exposição de populações humanas a metais pesados no ambiente: exemplos do Recôncavo Baiano. Química Nova, São Paulo/SP, v. 15, n. 2, p. 147-154, 1992. 